Gazi University
Journal of Science
http://dergipark.gov.tr/gujs

\title{
Decolorization of Reactive Black 5 Using N-Doped $\mathrm{TiO}_{2}$
}

\author{
Asli BERKTAS (D), Ozlem Esen KARTAL* (D) \\ Inonu University, Department of Chemical Engineering, 440280, Malatya, Turkey
}

Highlights

- Improvement of decolorization efficiency of $\mathrm{TiO}_{2}$ was observed doping with nitrogen.

- An optimum molar ratio of N/Ti was determined to be 3 for decolorization of RB5 in this study.

- Outdoor sunlight.could be used for remediation of textile effluents in Turkey.

Article Info

Received: 20 Nov 2020 Accepted: 01 June 2021

\section{Keywords}

\section{Sol-gel}

Nitrogen doping

Photocatalysis

Reactive Black 5

Solar light

\begin{abstract}
Decolorization of Reactive Black 5 (RB5) was investigated by heterogeneous photocatalysis using N-doped $\mathrm{TiO}_{2}$. N-doped $\mathrm{TiO}_{2}$ photocatalysts were synthesized by means of a sol-gel process. The characterization of synthesized samples was performed by X-ray diffraction, scanning electron microscopy and X-ray photoelectron spectroscopy measurements. Photocatalytic activity of $\mathrm{N}$-doped $\mathrm{TiO}_{2}$ samples was assessed by following decolorization and degradation efficiency of $\mathrm{RB} 5 . \mathrm{N}-\mathrm{TiO}_{2}(3)$ sample yielded the highest decolorization efficiency. The apparent first-order rate constants for decolorization of RB5 with $\mathrm{N}-\mathrm{TiO}_{2}(\mathrm{X})$ samples followed the order of $\mathrm{N}_{-} \mathrm{TiO}_{2}(3)>\mathrm{N}-\mathrm{TiO}_{2}(2)>\mathrm{N}-\mathrm{TiO}_{2}(4)>\mathrm{N}-\mathrm{TiO}_{2}(1)$. Improvement of decolorization efficiency of $\mathrm{TiO}_{2}$ was observed doping with nitrogen. The effect of actual sunlight on decolorization efficiency was also investigated. $96 \%$ and $49 \%$ of decolorization efficiency levels were attained within 60 minutes of reaction time with outdoor sunlight and fluorescent daylight lamps, respectively.
\end{abstract}

\section{INTRODUCTION}

Physical, chemical and biological processes have been applied for decontamination of industrial wastewater so far. They, however, either become inefficient in the presence of non-biodegradable organic compounds or involve further treatments [1-3]. Titanium dioxide $\left(\mathrm{TiO}_{2}\right)$ based heterogeneous photocatalysis appears to be an alternative process to degrade hazardous organic pollutants found in water bodies. The basic mechanisms of photocatalysis with illuminated $\mathrm{TiO}_{2}$ are well established [4-6].Organic pollutants are degraded by powerful hydroxyl radicals $(\cdot \mathrm{OH})$ produced via absorption of $\mathrm{UV}$ light by $\mathrm{TiO}_{2}$ in this treatment method. The band gap of energy of anatase is reported as $3.2 \mathrm{eV}$ and that of rutile is $3.0 \mathrm{eV}$ [7]. A wide band gap of $\mathrm{TiO}_{2}$ involves UV irradiation $(\lambda<400 \mathrm{~nm})$ due to requirement of higher photon energy. In an attempt to utilize solar energy and to promote photocatalytic efficiency of $\mathrm{TiO}_{2}$, doping with non-metal elements such as nitrogen $(\mathrm{N})[8-11]$, sulfur $(\mathrm{S})[12,13]$ and carbon $(\mathrm{C})[14,15]$ has been employed. Among these elements, doping $\mathrm{TiO}_{2}$ with nitrogen was accepted as the most effective as a visible photocatalyst $[9,11]$. Several efforts have been spent to increase photocatalytic efficiency of $\mathrm{TiO}_{2}$ using visible light after Asahi et al., [11] investigated shifting absorption edge of $\mathrm{TiO}_{2}$ into visible light by nitrogen doping. $\mathrm{TiO}_{2}$ can be doped with nitrogen by physical methods, including ball milling, ion implantation and sputtering and chemical methods, including sol-gel, hydrothermal and solvothermal [11]. $\mathrm{TiO}_{2}$ can be doped with nitrogen atoms substitutional or interstitial. If some lattice $\mathrm{O}$ atoms are substituted by $\mathrm{N}$ atoms, the chemical state of $\mathrm{N}$ is called substitutional, while addition of nitrogen atoms into lattice resulted in interstitial doping. Preparation methods affect the nitrogen doping in $\mathrm{TiO}_{2}$, in such a way that heating in $\mathrm{NH}_{3}$ flow, ion implantation and sputtering resulted in substitutional doping while nitrogen is incorporated interstitially in liquid phase preparation at low temperature [16]. 
Textile industry produces large amount of wastewater as a consequences of the requirement of nearly 21$377 \mathrm{~m}^{3}$ water/ton of product [17]. The utilization of a variety of chemicals including dyes, salts and surfactants in different textile operations makes textile wastewater extremely polluted. Effluents from textile industry can be identified with low biological oxygen demand (BOD)/chemical oxygen demand (COD) ratio (0.06-0.35), intense color and high concentration of salts [18]. Reactive dyes are widely used in cotton dyeing process of textile industry and up to $50 \%$ of unfixed dye is present in textile wastewater due to low fixation efficiency of them. Azo dyes have chromophore group of azo $(-\mathrm{N}=\mathrm{N}-)$. Their complex aromatic structures, toxic effects and non-biodegradability nature involve considering a proficient technology for remediation of textile wastewater [19]. The release of colored wastewater into aquatic environments has a detrimental effect on photosynthetic mechanism by reducing light penetration [20]. In this regard, $\mathrm{TiO}_{2}$ based heterogeneous photocatalysis has been applied for the removal of azo dyes [21-22]. Besides, $\mathrm{N}$-doped $\mathrm{TiO}_{2}$ was also applied in the degradation of dyes. Collazzo et al. [23] studied the degradation of Direct Black 38 using $\mathrm{N}$-doped anatase $\mathrm{TiO}_{2}$ irradiated under visible and sunlight. They observed higher degree of degradation with visible light. Fu et al. [10] prepared $\mathrm{N}$-doped $\mathrm{TiO}_{2}$ via solidstate calcination of titanate nanotubes using $\mathrm{NH}_{4} \mathrm{Cl}$. They reported that higher degradation efficiency were achieved with all prepared $\mathrm{N}$-doped $\mathrm{TiO}_{2}$ samples under visible light.Yeber et al. [24] investigated degradation of Remazol Brilliant Blue $\mathrm{R}$ with $\mathrm{N}$-doped $\mathrm{TiO}_{2}$ using Box-Benhken experimental design technique. At optimum conditions $86.3 \%$ dye removal was observed, whereas 50\% TOC removal was achieved.

The purpose of present study is to synthesize $\mathrm{N}$-doped $\mathrm{TiO}_{2}$ photocatalysts and to assess photocatalytic activity of them by following the decolorization efficiency of Reactive Black 5 (RB5) which is classified as diazo dye. In spide of existence of research papers on synthesis of $\mathrm{N}$-doped $\mathrm{TiO}_{2}$ in the literature, exploring the possibility of using outdoor sunlight is crucial for remediation of textile effluent in Turkey. Besides, the results of this study will give insight for further studies.

\section{MATERIALS AND METHOD}

\subsection{Materials}

Titanium tetraisopropoxide (TTIP, 97\%, Sigma-Aldrich), anhydrous ethyl alcohol (EtOH, Merck), $\mathrm{HNO}_{3}$ (70\%, Sigma-Aldrich) and $\mathrm{NH}_{3}(26 \%$, Sigma-Aldrich), $\mathrm{HCl}$ (37\%, Merck) and $\mathrm{NaOH}$ (Sigma-Aldrich) were used in this study. RB5 was supplied from DyStar.

\subsection{Preparation of Catalysts}

$\mathrm{TiO}_{2}$ was doped with nitrogen atoms at N/Ti molar ratios of 1-4 via sol-gel process using $\mathrm{NH}_{3}$ as a source of doping. In the synthesis of $\mathrm{N}$-doped $\mathrm{TiO}_{2}$ samples, $10 \mathrm{ml}$ of TTIP was dissolved in $40 \mathrm{ml}$ anhydrous EtOH. Another solution of $10 \mathrm{ml}$ anhydrous $\mathrm{EtOH}, 12 \mathrm{ml}$ diluted $\mathrm{HNO}_{3}$ and requisite amount of $\mathrm{NH}_{3}$ was prepared and added drop wise to the first solution under continuous stirring. The obtained sol was stirred at ambient temperature for 2 hours and kept in dark for 6 hours. After aging period, the resultant gel was put in an oven to dry at $80^{\circ} \mathrm{C}$ for 36 hours [9]. Then, $\mathrm{N}$-doped $\mathrm{TiO}_{2}$ samples were calcined at $450^{\circ} \mathrm{C}$ for 4 hours. Undoped $\mathrm{TiO}_{2}$ sample was synthesized without adding $\mathrm{NH}_{3}$. The synthesized $\mathrm{N}$-doped $\mathrm{TiO}_{2}$ samples were represented as $\mathrm{N}-\mathrm{TiO}_{2}(\mathrm{X})$ where $\mathrm{X}$ stands for nominal molar ratios of $\mathrm{N} / \mathrm{Ti}$.

\subsection{Characterization of Catalysts}

Determination of crystal phases of synthesized photocatalyst samples was performed by X-ray diffractometer (Rigaku RadB-DMax II) with $\mathrm{CuK} \alpha$ radiation. X-ray photoelectron spectroscopy (XPS) analyses of $\mathrm{N}^{-\mathrm{TiO}_{2}}$ (3) were performed using SPECS EA 300 spectrometer. Scanning electron microscope image with energy dispersive X-ray analysis (SEM-EDX) was recorded by LFO EVO40 instrument. 


\subsection{Catalytic Experiments}

Photocatalytic tests of synthesized $\mathrm{N}-\mathrm{TiO}_{2}(\mathrm{X})$ photocatalysts were assessed by following decolorization and degradation of RB5 under irradiation of fluorescent daylight lamps (Eiko, F8T5/DL) and outdoor sunlight in water jacketed quartz photoreactor. $0.5 \mathrm{~g}$ photocatalyst was added to RB5 solution at an initial concentration of $20 \mathrm{mg} \mathrm{L}^{-1}$ and magnetic stirring of resulting suspension in dark for $30 \mathrm{~min}$ was applied to observe an adsorption. A circular gas distributor was used to bubble oxygen gas into photoreactor from bottom. Reaction was initiated by turning on the lamps placed around of photoreactor. The $\mathrm{pH}$ of the solution was adjusted to 6 by using either dilute $\mathrm{NaOH}$ or $\mathrm{HCl}$ solutions and measured by a digital $\mathrm{pH}$ meter (Hanna pH-221). During illumination temperature of reaction medium was kept constant at $21 \pm 2^{\circ} \mathrm{C}$. Aliquots taken from reaction medium were centrifuged and filtered by syringe filter. The residual amount of RB5 was determined by UV-VIS spectrophotometer (UV-1800 Shimadzu). Decolorization and degradation efficiencies were calculated using Equations (1) and (2), respectively. Experiment under outdoor sunlight was performed between 10:00 and 15:00 h in July at Inonu University campus in Malatya province $\left(38^{\circ} 19^{\prime} \mathrm{E}, 38^{\circ} 21^{\prime} \mathrm{N}\right)$ in Turkey. Decolorization and degradation efficiencies were calculated using Equations (1) and (2), respectively.

Decolorization $\%=\frac{A_{0}(596 \mathrm{~nm})-\mathrm{A}(596 \mathrm{~nm})}{\mathrm{A}_{0}(596 \mathrm{~nm})} \times 100$

Degradation $\%=\frac{A_{0}(310 \mathrm{~nm})-\mathrm{A}(310 \mathrm{~nm})}{\mathrm{A}_{0}(310 \mathrm{~nm})} \times 100$

where $\mathrm{A}_{\mathrm{o}}$ and $\mathrm{A}$ are absorbance values of $\mathrm{RB} 5$ at $\mathrm{t}=0$ and $\mathrm{t}=\mathrm{t}$ with corresponding wavelengths, respectively.

\section{RESULTS AND DISCUSSIONS}

\subsection{XRD Analysis}

XRD spectra of undoped and $\mathrm{N}$-doped $\mathrm{TiO}_{2}$ photocatalysts with different starting molar ratios of N/Ti are given in Figure 1. As we reported in our previous study, although all samples showed crystallized structure, compared to $\mathrm{N}$-doped samples, undoped $\mathrm{TiO}_{2}$ had lower crystallinity [25]. The anatase and rutile composition was determined using XRD spectrum data by Spurr-Myers equation:

$X_{A}(\%)=\frac{1}{1+1.26 \frac{I_{R}}{I_{A}}} \times 100$

where $\mathrm{X}_{\mathrm{A}}$ is the mass percent of anatase, $\mathrm{I}_{\mathrm{R}} / \mathrm{I}_{\mathrm{A}}$ is the ratio of peak intensity of rutile phase (110) to that of anatase phase (101) [26]. Obviously, a major peak of anatase at $2 \theta=25.520^{\circ}$ which is pertinent to 101 reflection and a major peak of rutile at $2 \theta=27.481^{\circ}$ which is pertinent to 110 reflection were observed for undoped sample. Anatase phase was found to be $54 \%$ for undoped $\mathrm{TiO}_{2}$ sample, whereas only anatase phase was observed for all $\mathrm{N}$-doped $\mathrm{TiO}_{2}$ samples. Nitrogen doping of $\mathrm{TiO}_{2}$ enhanced the evolvement of anatase phase and inhibited rutile phase formation [27].

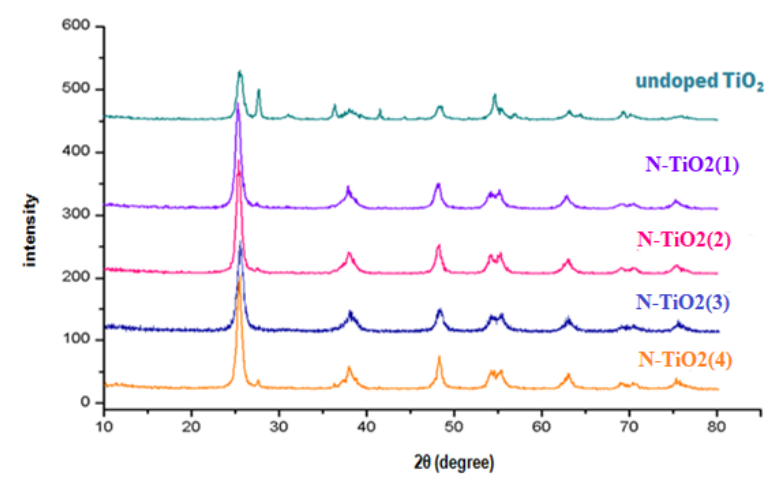

Figure 1. XRD patterns of undoped and $\mathrm{N}-\mathrm{TiO}_{2}(x)$ samples 


\subsection{XPS Analyses}

Chemical state of doped $\mathrm{N}$ atoms was determined via XPS analyses. The whole spectrum of $\mathrm{N}-\mathrm{TiO}_{2}(3)$ sample presented in Figure 2a reveals that the surface of sample consists of $\mathrm{Ti}, \mathrm{O}$ and $\mathrm{N}$ with $\mathrm{C}$ as contaminant. The intensity of $\mathrm{N} 1 \mathrm{~s}$ peak was very low compared to those of $\mathrm{Ti}$ and $\mathrm{O}$ due to low amount of $\mathrm{N}$. The $\mathrm{N}$ 1s spectrum of $\mathrm{N}_{-}-\mathrm{TiO}_{2}$ (3) is given in Figure 2b. It is accepted that peak at $396.4 \mathrm{eV}$ is ascribed to substitutional nitrogen involving replacement of oxygen by nitrogen and formation of Ti-N bonds. The peak observed at $398.5 \mathrm{eV}$ is due to substitutional nitrogen to form O-Ti-N bonds. The peak at the binding energy of $399.0 \mathrm{eV}$ represents interstitial nitrogen doping that involves binding nitrogen atom to lattice oxygen $[28,29]$. As can be seen in $\mathrm{N}$ 1s spectrum of $\mathrm{N}-\mathrm{TiO}_{2}(3)$ sample, both interstitial and substitutional nitrogen doping occurred. This is also observed by other authors [9,11]. Peaks at the binding energies greater than $400 \mathrm{eV}$ are attributed to oxidized nitrogen species chemically adsorbed on the surface $[28,30]$. The Ti $2 \mathrm{p}$ spectrum of $\mathrm{N}-\mathrm{TiO}_{2}(3)$ sample is given in Figure $2 \mathrm{c}$. This spectrum exhibits Ti $2 \mathrm{p}_{3 / 2}$ and $\mathrm{Ti} 2 \mathrm{p}_{1 / 2}$ peaks with corresponding binding energies of 457.5 and $463.2 \mathrm{eV}$, respectively. According to literature, commercial $\mathrm{P} 25-\mathrm{TiO}_{2}$ shows core level peaks of $\mathrm{Ti} 2 \mathrm{p}_{3 / 2}$ and $\mathrm{Ti} 2 \mathrm{p}_{1 / 2}$ at 458.9 and $464 . \mathrm{eV}$, respectively. Nitrogen doping resulted in decrease in binding energy of Ti $2 \mathrm{p}_{3 / 2}$ and Ti $2 \mathrm{p}_{1 / 2}$ levels. A decrease in binding energy of $\mathrm{Ti} 2 \mathrm{p}_{3 / 2}$ indicates that $\mathrm{Ti}^{+4}$ is reduced to $\mathrm{Ti}^{+3}$ due to existence of substitutional nitrogen atoms $[16,28,31]$. The $\mathrm{O} 1 \mathrm{~s}$ spectrum of $\mathrm{N}-\mathrm{TiO}_{2}(3)$ sample given in Figure $2 \mathrm{~d}$ indicates a peak at $528 \cdot 7 \mathrm{eV}$. Since $\mathrm{P} 25-\mathrm{TiO}_{2}$ exhibits $\mathrm{O} 1 \mathrm{~s}$ peak at $530.3 \mathrm{eV}$, the results indicated that binding energy of $\mathrm{O} 1 \mathrm{~s}$ peak of $\mathrm{N}-\mathrm{TiO}_{2}$ (3) sample decreased after nitrogen doping.
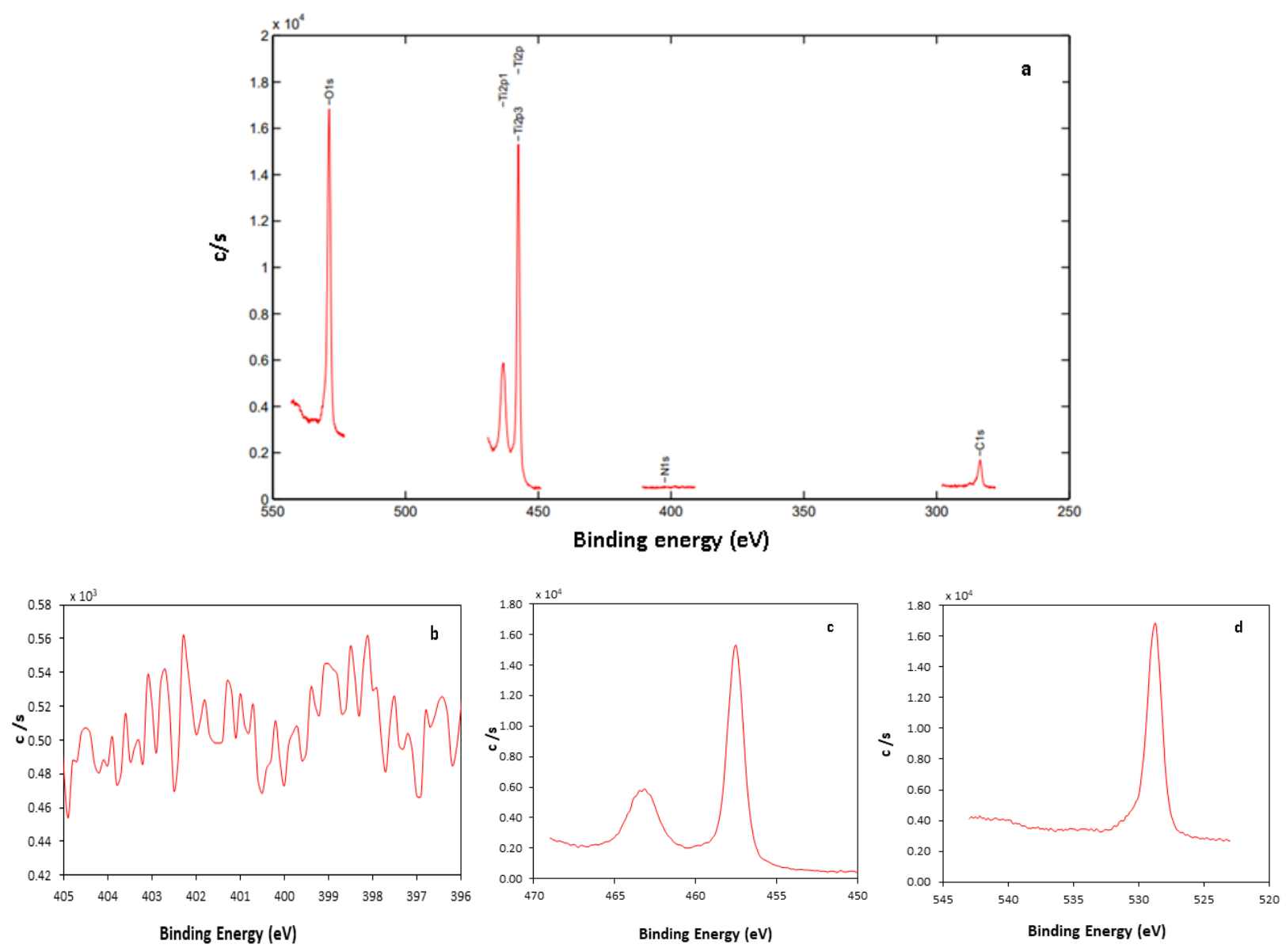

Figure 2. XPS spectra of $\mathrm{N}-\mathrm{TiO}_{2}(3)$ sample(a) survay, (b) N1s, (c) Ti2p, (d) Ols 


\subsection{SEM Analysis}

Figure 3a reveals SEM image of $\mathrm{N}_{-} \mathrm{TiO}_{2}$ (3) sample. Apparently, particles with spherical shape and agglomeration of them were observed. Circles show the particles whose EDX spectrum was recorded. Figure $3 \mathrm{~b}$ shows EDX spectrum of particle indicted by arrow. Besides, elemental composition of that particle confirms presence of nitrogen in the sample.

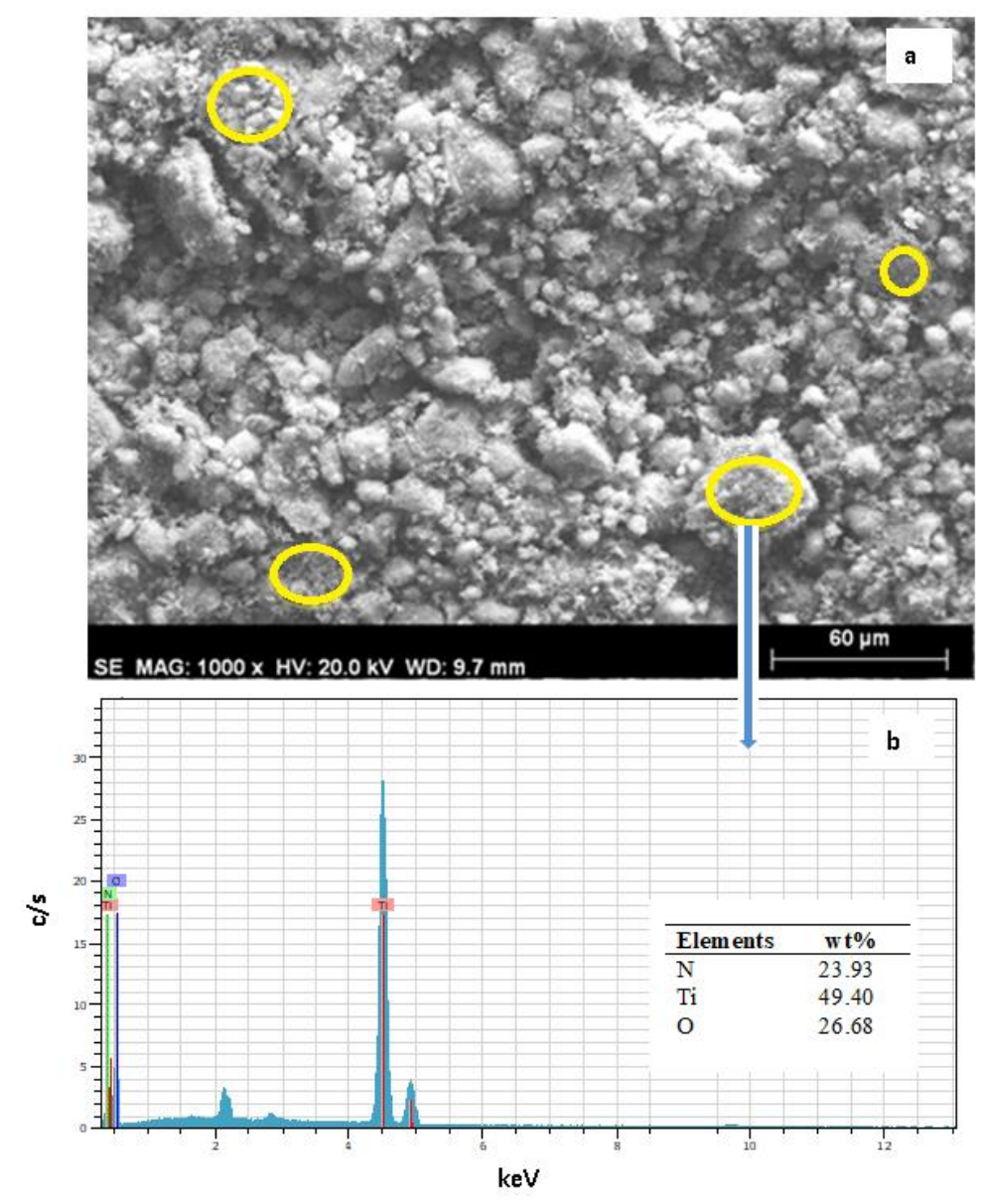

Figure 3. (a) SEM image of $\mathrm{N}-\mathrm{TiO}_{2}$ (3) (b) EDX spectrum

\subsection{Investigation of Photocatalytic Efficiency}

Decolorization of RB5 was tested using $2 \mathrm{~g} \mathrm{dm}^{-3}$ photocatalyst with $20 \mathrm{mg} \mathrm{dm}^{-3}$ initial RB5 concentration. Figure 4 shows that only about $10 \%$ of decolorization by adsorption in dark was observed with all samples and $39 \%, 38 \%, 64 \%, 72 \%$ and $57 \%$ decolorization efficiency values were obtained after 120 min with undoped, $\mathrm{N}-\mathrm{TiO}_{2}(1), \mathrm{N}-\mathrm{TiO}_{2}(2), \mathrm{N}-\mathrm{TiO}_{2}(3)$ and $\mathrm{N}-\mathrm{TiO}_{2}(4)$ samples, respectively. Upon 300 min of reaction time, a complete decolorization was obtained with $\mathrm{N}-\mathrm{TiO}_{2}(2), \mathrm{N}^{-\mathrm{TiO}_{2}}(3)$ and $\mathrm{N}-\mathrm{TiO}_{2}(4)$. All N-doped $\mathrm{TiO}_{2}$ samples showed improved decolorization efficiency compared to undoped $\mathrm{TiO}_{2}$. Inhibition of recombination of photogenerated electron-hole pairs by nitrogen atoms enhanced the photocatalytic activity due to alteration of the electronic properties of $\mathrm{TiO}_{2}$ [32]. Among $\mathrm{N}$-doped $\mathrm{TiO}_{2}, \mathrm{~N}-\mathrm{TiO}_{2}(3)$ indicated the highest photocatalytic decolorization rate. It can be deduced from this result that there is an optimum dopant concentration. Amount of chemically adsorbed nitrogen increases with increasing N/Ti ratio. Coating of catalyst surface with chemically adsorbed nitrogen resulted in decrease of the number of active sites [33]. 


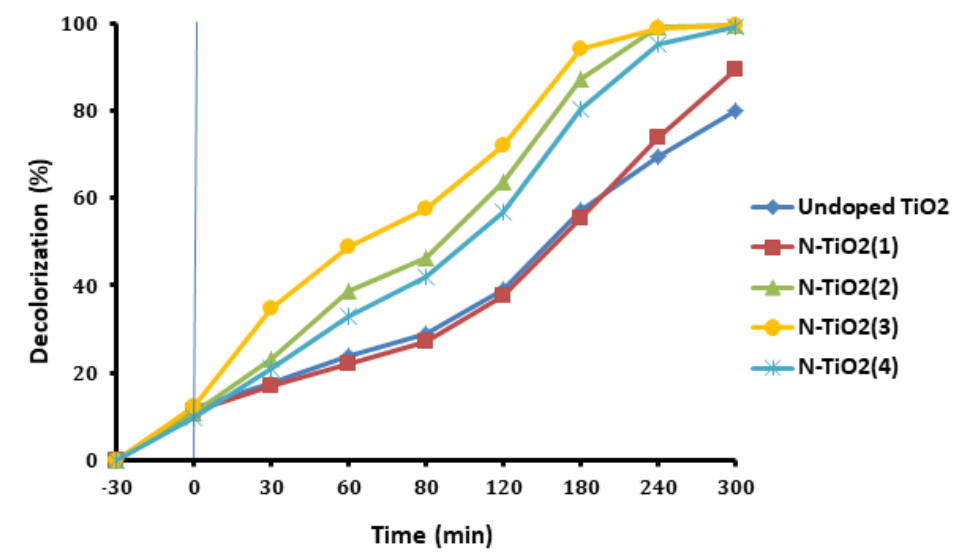

Figure 4. Decolorization of RB5

$\left(\mathrm{pH}=6,[\mathrm{RB} 5]=20 \mathrm{mg} \mathrm{dm} \mathrm{m}^{-3},\left[\mathrm{TiO}_{2}\right]_{\text {doped or undoped }}=2 \mathrm{~g} \mathrm{dm}^{-3}\right)$

Decolorization of RB5 can be expressed as pseudo first order kinetics given in Equation (4) [34]

$r=-\frac{d C}{d t}=k_{a p p} C$

where $\mathrm{k}_{\mathrm{app}}$ is apparent first-order rate constant.

Integration of Equation (4) from $C_{0}$ to $C$ yielded Equation (5)

$\ln \frac{C_{o}}{C}=k_{a p p} \mathrm{t}$

where $\mathrm{C}_{\mathrm{o}}$ and $\mathrm{C}$ are concentrations of RB5 at $\mathrm{t}=0$ and $\mathrm{t}=\mathrm{t}$, respectively. As depicted from Figure 5, a linear relation attained by plotting $\ln \left(\mathrm{C}_{\mathrm{o}} / \mathrm{C}\right)$ versus $\mathrm{t}$ for undoped and $\mathrm{N}-\mathrm{TiO}_{2}(\mathrm{X})$ samples. $\mathrm{k}_{\text {app }}$ values for decolorization of RB5 obtained from the slope of plots and correlation constants are represented in Table 1. $\mathrm{N}-\mathrm{TiO}_{2}(3)$ sample yielded the highest $\mathrm{k}_{\text {app }}$ value, indicating that $\mathrm{N}-\mathrm{TiO}_{2}(3)$ was determined as the most efficient photocatalyst for RB5 degradation in this study.

Table 1. $k_{\text {app }}$ values for decolorization of RB5

\begin{tabular}{lll}
\hline Sample & $k_{a p p}\left(\mathrm{~min}^{-1}\right)$ & $\mathrm{R}^{2}$ \\
\hline Undoped $\mathrm{TiO}_{2}$ & 0.0030 & 0.9856 \\
$\mathrm{~N}-\mathrm{TiO}_{2}(1)$ & 0.0030 & 0.9799 \\
$\mathrm{~N}-\mathrm{TiO}_{2}(2)$ & 0.0074 & 0.9859 \\
$\mathrm{~N}-\mathrm{TiO}_{2}(3)$ & 0.0093 & 0.9955 \\
$\mathrm{~N}-\mathrm{TiO}_{2}(4)$ & 0.0061 & 0.9893 \\
\hline
\end{tabular}




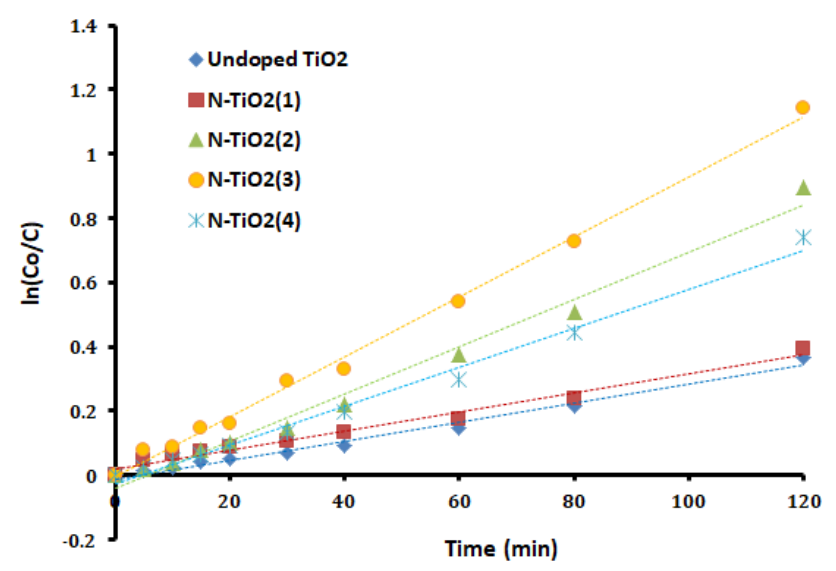

Figure 5. Pseudo first order kinetics plots of decolorization of RB5

$\left(\mathrm{pH}=6,[\mathrm{RB} 5]=20 \mathrm{mg} \mathrm{dm}-3,\left[\mathrm{TiO}_{2}\right]_{\text {doped or undoped }}=2 \mathrm{~g} \mathrm{dm}^{-3}\right)$

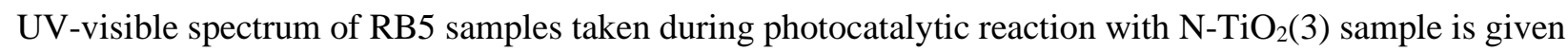
in Figure 6. The band at $596 \mathrm{~nm}$ represents azo chromophore group of dye. Since decolorization is result of breaking of $-\mathrm{N}=\mathrm{N}$ - bonds, decolorization was determined using absorbance values at $596 \mathrm{~nm}$. The band at $310 \mathrm{~nm}$ corresponds to aromatic content of the dye and degradation was determined using absorbance values at $310 \mathrm{~nm}$. Both of the peaks were progressively decreased during irradiation time. It is clearly evident from Figure 7 that aromatic degradation is lesser (88.3\%) than decolorization. Almost complete decolorization was obtained after 300 minutes but aromatic degradation required longer time. Because $\mathrm{N}=\mathrm{N}$ - bonds was attacked firstly by $\mathrm{OH}$, thus providing decolorization as a result of cleavage of these bonds [35].

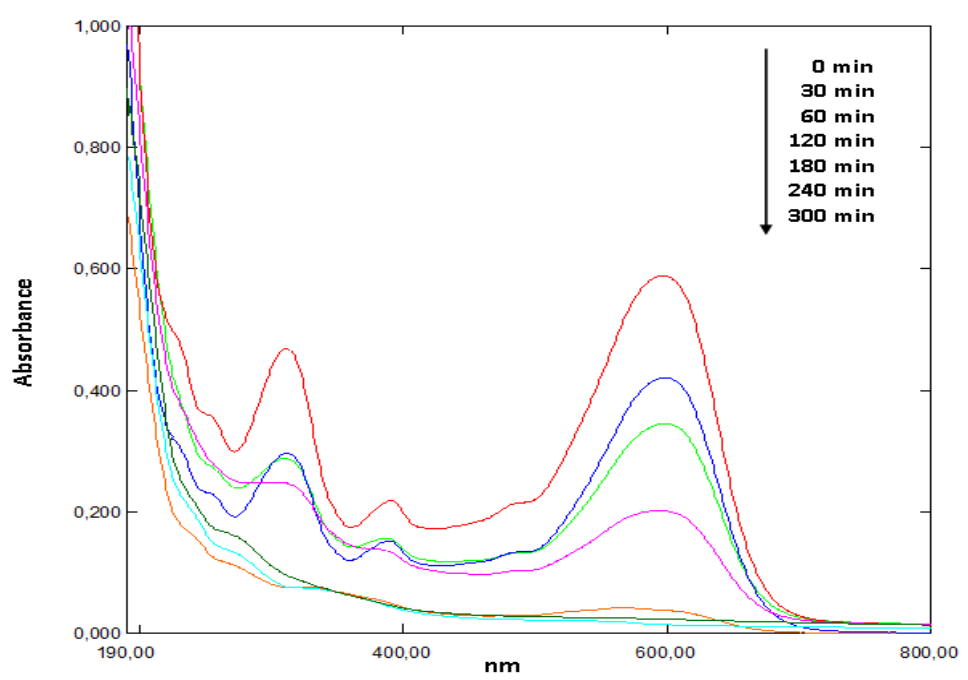

Figure 6. UV-visible spectra of RB5 samples taken during photocatalytic reaction with $\mathrm{N}-\mathrm{TiO}_{2}(3)$ sample $\left(\mathrm{pH}=6,[\mathrm{RB} 5]=20 \mathrm{mg} \mathrm{dm} \mathrm{m}^{-3}, \mathrm{~N}-\mathrm{TiO}_{2}(3)=2 \mathrm{~g} \mathrm{dm}^{-3}\right)$ 


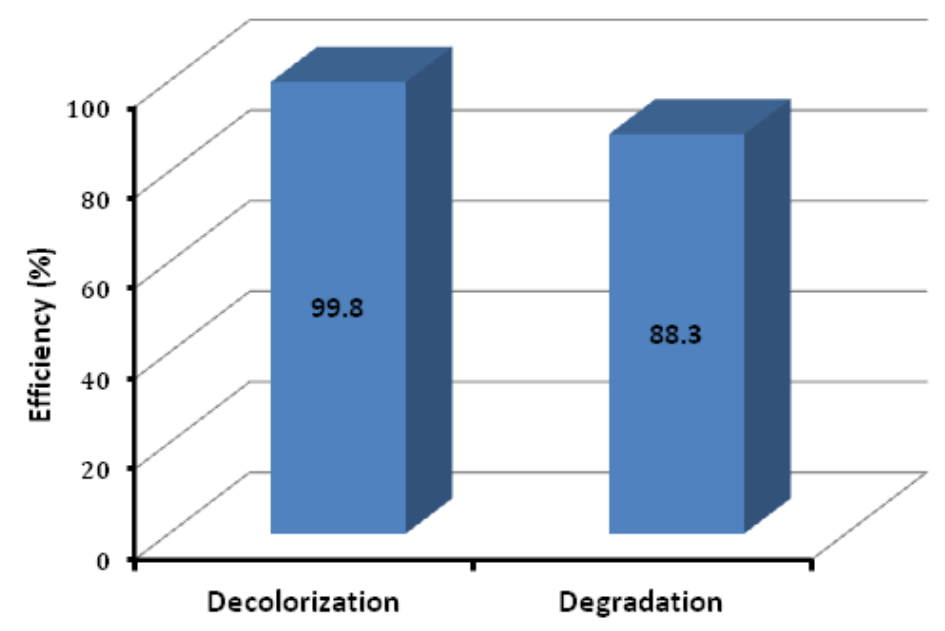

Figure 7. Decolorization and aromatic degradation of $R B 5$ $\left(\mathrm{pH}=6,[\mathrm{RB} 5]=20 \mathrm{mg} \mathrm{dm}^{-3}, \mathrm{~N}-\mathrm{TiO}_{2}(3)=2 \mathrm{~g} \mathrm{dm}^{-3}, t=300 \mathrm{~min}\right)$

Figure 8 reveals the decolorization RB5 under different illumination conditions. Exposing the suspension of $2 \mathrm{~g} \mathrm{dm}^{-3} \mathrm{~N}^{-\mathrm{TiO}_{2}}$ (3) sample using $20 \mathrm{mg} \mathrm{dm}^{-3}$ initial RB5 concentration to outdoor sunlight irradiation yielded $96 \%$ of decolorization within 60 minutes, while $49 \%$ of that was obtained with fluorescent daylight lamps. In addition, in the case of direct photolysis (i.e. in the absence of photocatalyst) negligible level of decolorization was observed. Monthly average global solar radiation of Malatya and Turkey in July is 7.596 and $6.903 \mathrm{kWh} / \mathrm{m}^{2}$ day, respectively [36]. These results suggest that it is reasonable to use solar energy for treatment of textile effluents in Turkey. The operating cost of photocatalytic oxidation processes mainly comprise of the cost of electrical energy of lamps used to illuminate $\mathrm{TiO}_{2}$. Therefore, it would be beneficial solar light to reduce the cost of treatment.

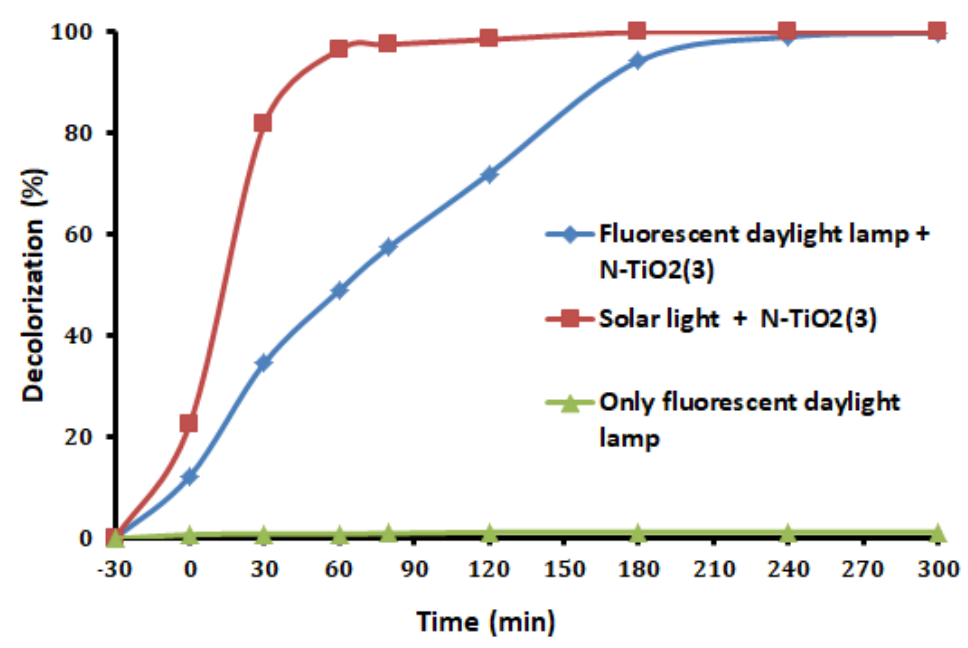

Figure 8. Decolorization of RB5 under different illumination conditions $\left(\mathrm{pH}=6,[\mathrm{RB} 5]=20 \mathrm{mg} \mathrm{dm}^{-3}\right)$

\section{CONCLUSION}

In this study, decolorization of RB5 using $\mathrm{N}$-doped $\mathrm{TiO}_{2}$ was examined under fluorescent daylight lamp and outdoor sunlight irradiation. $\mathrm{N}$-doped $\mathrm{TiO}_{2}$ photocatalysts were prepared via sol-gel process. $\mathrm{N} 1 \mathrm{~s}$ spectrum of $\mathrm{N}-\mathrm{TiO}_{2}(3)$ sample indicated that both interstitial and substitutional nitrogen doping was observed. Nitrogen doping improved the decolorization efficiency of $\mathrm{TiO}_{2}$ by inhibiting electron-hole pair 
recombination. $\mathrm{N}-\mathrm{TiO}_{2}(3)$ sample exhibited the highest photocatalytic decolorization. Decolorization of RB5 can be expressed as pseudo first order kinetics and $\mathrm{k}_{\text {app }}$ values increased as molar ratio of N/Ti increased from 1 to 3. Decolorization efficiency was higher than degradation efficiency for RB5 dye. The result obtained with outdoor sunlight suggests that high solar energy potential of Turkey could be used for remediation of textile wastewater.

\section{CONFLICTS OF INTEREST}

No conflict of interest was declared by the authors.

\section{ACKNOWLEDGEMENT}

The authors are grateful to the Scientific and Technological Research Council of Turkey for financial support.

\section{REFERENCES}

[1] Holkar, C. R., Jadhav, A. J., Pinjari, D. V., Mahamuni, N.M., Pandit, A.B., “A critical review on textile wastewater treatments: Possible approaches", Journal of Environmental Management, 182: 351-366, (2016).

[2] Rodriguez-Narvaez, O.M., Peralta-Hernandez, J.M., Goonetilleke, A., Bandala, E.R., "Treatment technologies for emerging contaminants in water: A review", Chemical Engineering Journal, 323: 361-380, (2017).

[3] Shahidi, D., Roy, R., Azzouz, A., "Advances in catalytic oxidation of organic pollutants - Prospects for thorough mineralization by natural clay catalysts", Applied Catalysis B-Environmental, 174175: 277-292, (2015).

[4] Al-Mamun, M.R., Kader, S., Islam, M.S., Khan, M.Z.H., "Photocatalytic activity improvement and application of $\mathrm{UV}-\mathrm{TiO}_{2}$ photocatalysis in textile wastewater treatment: A review", Journal of Environmental Chemical Engineering, 7: 103248, (2019).

[5] Wetchakuna, K., Wetchakunb, N., Sakulsermsuk, S., "An overview of solar/visible light-driven heterogeneous photocatalysis for water purification: $\mathrm{TiO}_{2}$ - and $\mathrm{ZnO}$-based photocatalysts used in suspension photoreactors", Journal of Industrial and Engineering Chemistry, 71:19-49, (2019).

[6] He, X., Wang, A., Wu, P., Tang, S., Zhang, Y., Li, L., Ding, P., "Photocatalytic degradation of microcystin-LR by modified $\mathrm{TiO}_{2}$ photocatalysis: A review", Science of The Total Environment, 743: 140694, (2020).

[7] Perillo, P.M., Rodríguez, D.F., "Photocatalysis of Methyl Orange using free standing TiO2 nanotubes under solar light", Environmental Nanotechnology, Monitoring \& Management, 16: 100479, (2021).

[8] Asahi, R., Morikawa, T., Ohwaki, T., Aoki, K., Taga, Y., "Visible-light photocatalysis in nitrogendoped titanium oxides", Science, 293: 269-271, (2001).

[9] Cheng, X., Yu, X., Xing, Z., "Characterization and mechanism analysis of $\mathrm{N}$ doped $\mathrm{TiO}_{2}$ with visible light response and its enhanced visible activity", Applied Surface Science, 258(7): 32443248, (2012). 
[10] Fu, J., Tian, Y., Chang, B., Xi, F., Dong, X., "Facile fabrication of $\mathrm{N}$-doped $\mathrm{TiO}_{2}$ nanocatalyst with superior performance under visible light irradiation", Journal of Solid State Chemistry, 199: 280286, (2013).

[11] Ansari, S.A., Khan, M.M., Ansari, M. O., Cho, M.H., "Nitrogen-doped titanium dioxide (N-doped $\mathrm{TiO}_{2}$ ) for visible light photocatalysis", New Journal of Chemistry, 40: 3000-3009, (2016).

[12] Tian, G., Pan, K., Fu, H., Jing, L., Zhou, W., "Enhanced photocatalytic activity of S-doped $\mathrm{TiO}_{2-}$ $\mathrm{ZrO}_{2}$ nanoparticles under visible-light irradiation", Journal of Hazardous Materials, 166: 939-944, (2009).

[13] McManamon, C., O’Connell, J., Delaney, P., Rasappa, S., Holmes, J. D., Morris, M. A., “A facile route to synthesis of $\mathrm{S}$-doped $\mathrm{TiO}_{2}$ nanoparticles for photocatalytic activity", Journal of Molecular Catalysis A: Chemical, 406: 51-57, (2015).

[14] Lin, Y.-T., Weng, C.-H., Lin, Y.-H., Shiesh, C., Chen, F.-Y., "Effect of C content and calcination temperature on the photocatalytic activity of $\mathrm{C}$-doped $\mathrm{TiO}_{2}$ catalyst", Separation and Purification Technology, 116: 114-123, (2013).

[15] Sullivan, J.J.A., Neville, E.M., Herron, R., Thampi, K. R., Mac Elroy, J.M.D., "Routes to visible light active C-doped $\mathrm{TiO}_{2}$ photocatalysts using carbon atoms from the Ti precursors", Journal of Photochemistry and Photobiology A: Chemistry, 289: 60-65, (2014).

[16] Peng, F., Cai, L., Yu, H., Wang, H., Yang, J., "Synthesis and characterization of substitutional and interstitial nitrogen-doped titanium dioxides with visible light photocatalytic activity", Journal of Solid State Chemistry, 181: 130-136, (2008).

[17] Asghar, A., Raman, A.A.A., Daud, W.M.A.W., "Advanced oxidation processes for in-situ production of hydrogen peroxide/hydroxyl radical for textile wastewater treatment: a review", Journal of Cleaner Production, 87: 826-838, (2015).

[18] Bilinska, L., Gmurek, M., Ledakowicz, S., "Comparison between industrial and simulated textile wastewater treatment by AOPs - Biodegradability, toxicity and cost assessment", Chemical Engineering Journal, 306: 550-559, (2016).

[19] Ambigadevi, J., Kumar, S.P., Vo, D.V. N., Haran, S.H., Raghavan, T.N.S., "Recent developments in photocatalytic remediation of textile effluent using semiconductor based nanostructured catalyst: A review", Journal of Environmental Chemical Engineering, 9: 104881, (2021).

[20] Selvaraj, V., Karthikaa, T.S., Mansiya, C., Alagar, M., "An over review on recently developed techniques, mechanisms and intermediate involved in the advanced azo dye degradation for industrial applications", Journal of Molecular Structure, 1224: 129195, (2021).

[21] Rochkind, M., Pasternak, S., Paz, Y., "Using dyes for evaluating photocatalytic properties: A critical review", Molecules, 20: 88-110, (2015).

[22] Akpan, U.G., Hameed, B.H., "Parameters affecting the photocatalytic degradation of dyes using $\mathrm{TiO}_{2}$-based photocatalysts: A review", Journal of Hazardous Materials, 170: 520-529, (2009).

[23] Collazzo, G.C., Foletto, E.L., Jahn, S.L., Villetti, M.A., "Degradation of Direct Black 38 dye under visible light and sunlight irradiation by $\mathrm{N}$-doped anatase $\mathrm{TiO}_{2}$ as photocatalyst", Journal of Environmental Management, 98: 107-111, (2012). 
[24] Yeber, M.C., Zamora, T., Álvarez, R., Medina, P., "N-doped titanium dioxide nanoparticles activated under visible light achieve the photocatalytic degradation of textile azo dye remazol brilliant blue R", Desalination and Water Treatment, 151: 161-166, (2019).

[25] Berktaş, A., Kartal, Ö.E., "Synthesis of N-Doped $\mathrm{TiO}_{2}$ by sol-gel method and investigation of its photocatalytic activity", $11^{\text {th }}$ National Congress on Chemical Engineering, Eskişehir, 174-177, (2014).

[26] Spurr, R.A., Myers, H., "Quantitative analysis of anatase-rutile mixtures with an X-Ray Diffractometer", Analytical Chemistry, 29: 760-762, (1957).

[27] Lin, Y. H., Chiu, T. C., Hsueh, H. T., Chu, H., "N-doped $\mathrm{TiO}_{2}$ photo-catalyst for the degradation of 1, 2-dichloroethane under fluorescent light", Applied Surface Science, 258: 1581-1586, (2011).

[28] Huang, W.C., Ting, J.M., "Novel nitrogen-doped anatase $\mathrm{TiO}_{2}$ mesoporous bead photocatalysts for enhanced visible light response", Ceramics International, 43(13): 9992-9997, (2017).

[29] Kalantari, K., Kalbasi, M., Sonrabi, M., Royaee, S.J., "Synthesis and characterization of N-doped $\mathrm{TiO}_{2}$ nanoparticles and their application in photocatalytic oxidation of dibenzothiophene under visible light", Ceramics International, 42(13): 14834-14842, (2016).

[30] Lee, S., Chou, I.S., Lee, D.K., Kim, D.W., Noh, T.H., Kwak, C.H., Park, S., Hong, K.S., Lee, J.K., Jung, H.S., "Influence of nitrogen chemical states on photocatalytic activities of nitrogen-doped $\mathrm{TiO}_{2}$ nanoparticles under visible light", Journal of Photochemistry and Photobiology A: Chemistry, 213: 129-135, (2010).

[31] Ma, Y., Zhang, J., Tian, B., Chen, F., Wang, L., "Synthesis and characterization of thermally stable $\mathrm{Sm}, \mathrm{N}$ co-doped $\mathrm{TiO}_{2}$ with highly visible light activity", Journal of Hazardous Materials, 182: 386$393,(2010)$.

[32] Gai, L., Mei, Q., Duan, X., Jiang, H., Zhou, G., Tian, Y., Lu, X., "Controlled synthesis of nitrogendoped binary and ternary $\mathrm{TiO}_{2}$ nanostructures with enhanced visible-light catalytic activity", Journal of Solid State Chemistry, 199: 271-279, (2013).

[33] Senthilnathan, J., Philip, L., "Photocatalytic degradation of lindane under UV and visible light using $\mathrm{N}$-doped $\mathrm{TiO}_{2}$ ", Chemical Engineering Journal, 161: 83-92, (2010).

[34] Din, M.İ., Khalid, R., Najeeb, J., Hussain, Z., "Fundamentals and photocatalysis of methylene blue dye using various nanocatalytic assemblies- a critical review", Journal of Cleaner Production, 298: 126567, (2021).

[35] Damodar, R.A., You, S. J., "Performance of an integrated membrane photocatalytic reactor for the removal of Reactive Black 5", Separation and Purification Technology, 71: 44-49, (2010).

[36] Turkish State Meteorological Service https://www.mgm.gov.tr/kurumici/radyasyon_iller.aspx?il=malatya. Access date: 06.05.2021 